\title{
Aspectos históricos da evolução e do reconhecimento internacional do status de refugiado*
}

\section{Historical aspects of the evolution and international recognition of the status of refugee}

Stefania Eugenia Barichello Luiz Ernani Bonesso de Araujo²

* Recebido em 09.09.2014

Aprovado em 10.10.2014

1 Doutoranda na School of Advanced Study da Universidade de Londres. Doctoral Affiliate da Refugee Law Initiative, Londres. Bolsista da CAPES - Processo n. 0796/14-0. Sua pesquisa tem como foco a proteção de refugiados e responsabilidade compartilhada na América Latina. Mestre em Human Rights and Democratisation (EIUC, Itália, e University of Uppsala, Suécia). Mestre em Comparative Study of Mercosur and the European Union (Università Degli Studi di Udine e Universidad Nacional de Cuyo). Mestre em Integração Latino-americana (UFSM). E-mail: stefania.barichello@postgrad.sas.ac.uk

2 Professor da Universidade Federal de Santa Maria no Programa de Pós-Graduação em Direito da Universidade Federal de Santa Maria e na graduação. Doutorado e mestrado em Direito pela Universidade Federal de Santa Catarina.

\section{Resumo}

Esse artigo visa investigar e apresentar uma visão geral da história do reconhecimento internacional do estatuto de refugiados e a sua consolidação. Para tanto, o artigo aborda a história do reconhecimento internacional do status de refugiado, de 1920-1950 conforme descrito por Hathaway (abordagem jurídica, social e individualista). Analisando a importância da Convenção de 1951 e o seu Protocolo de 1967. Finalmente, as conclusões destinam-se a sintetizar os principais aspectos desta pesquisa.

Palavras-chave: Convenção de 1951. Direito dos Refugiados. Direitos Humanos. Protocolo de 1967.

\begin{abstract}
The aim of this paper is to present an overview of the history of international recognition of the status of refugees and its consolidation. For this purpose, it is addresses the history of the international recognition of the status of refuges, from 1920-1950, as described by Hathaway (juridical, social and individualistic approach). Analysing the importance of the 1951 Convention and its Protocol. Finally, the conclusions are intended to summarise the main aspects and the outcome of this research.
\end{abstract}

Keywords: 1951 Convention. 1967 Protocol. Human Rights. Refugee Law. 


\section{Introdução}

Os deslocamentos forçados de grandes contingentes humanos vêm chamando a atenção da comunidade internacional. Nesses grupos que migram forçadamente se inserem os deslocados internos, os apátridas, os asilados, bem como o objeto deste estudo, os refugiados. Conforme a Convenção de Genebra de 1951, refugiados são aquelas pessoas que são obrigadas a abandonar sua terra natal e procurar a proteção de outros Estados por terem sido ameaçadas de perseguição (ou efetivamente perseguidas) por motivos de raça, religião, nacionalidade ou filiação a determinado grupo social ou político.

A presente pesquisa justifica-se como uma contribuição para os estudos referentes ao Direito Internacional dos Refugiados, ramo de crescente importância no Direito Internacional que se encontra, juntamente com o Direito Internacional Humanitário e o Direito Internacional dos Direitos Humanos configura as três vertentes de proteção internacional da pessoa humana (TRINDADE, 2003) ${ }^{3}$. No Brasil, o Direito Internacional dos Refugiados é uma área de crescente importância, devido ao aumento da sua participação no cenário internacional, por meio dos programas de reassentamento e do Plano de Ação do México e também pelo fato de estar recebendo grande incentivo à pesquisa e a produção acadêmica por parte do Alto Comissariado das Nações Unidas para Refugiados por meio da Cátedra Sérgio Vieira de Mello.

Este artigo visa proporcionar uma compreensão da constituição do instituto do refúgio e sua consolidação sob uma perspectiva coletiva (jurídico-social) e individualista, atentando para a Convenção de 1951 e o Protocolo de 1967, bem como fornecer bases teóricas para refletir sobre a problemática do refugiado. $\mathrm{O}$ artigo está dividido em três partes.

A primeira parte denominada a consolidação do Instituto do Refúgio, trata da perspectiva coletiva, tanto em sua abordagem jurídica (1920-1935) como social (1935-1939), e da perspectiva individualista (1938-1950),

3 Conforme Antônio Augusto Cançado Trindade, a proteção internacional da pessoa humana (ou Direitos Humanos Lato Sensu) divide-se em três vertentes: o Direito Internacional Humanitário, o Direito Internacional dos Direitos Humanos e o Direito Internacional dos Refugiados (TRINDADE, 2003).
A segunda discorre sobre o instrumento basilar na política de asilo, a Convenção de Genebra de 1951 e o seu protocolo de 1967. Apesar de originalmente concebida para lidar com a situação pós-Segunda Guerra Mundial na Europa, circunstâncias bastante diferentes de hoje, ainda representa um marco no surgimento de uma vontade global em resolver a questão do deslocamento forçado.

A segunda guerra mundial motivou $o$ reconhecimento internacional do status de refugiados, bem como um novo conceito de direitos humanos, resultantes de atrocidades cometidas durante o Holocausto e a emergente preocupação internacional com a dignidade humana. $\mathrm{O}$ instrumento-chave no reconhecimento da proteção dos refugiados são a Convenção de Genebra de 1951 e o seu protocolo de 1967 são considerados o alicerce do direito internacional dos refugiados. Originalmente concebido para lidar com a situação pós-Segunda Guerra Mundial na Europa, em circunstâncias bastante diferentes de hoje, ainda que representem um marco no surgimento de uma vontade global em solucionar a questão do deslocamento forçado.

\section{A consolidação do Instituto do Refúgio}

A implementação do Instituto do Refúgio deuse, num primeiro momento, por meio das atividades da Liga das Nações. A partir desse marco histórico, Fischel de Andrade divide essa primeira fase do estudo dos refugiados, de 1921 a 1951, em duas (FISCHEL DE ANDRADE, 1996). A primeira compreende o período de 1921 a 1939, no qual o conceito observava o grupo étnico ou nacional a que o refugiado pertencia (elemento objetivo), sendo ele, por conceituação, definido como membro de um determinado grupo de pessoas perseguidas em seu estado de origem. A segunda fase, de 1938 a 1951, caracteriza-se pela perspectiva individualista daquele que buscava proteção (elemento subjetivo), na qual o fator determinante para a análise da situação de refugiado era "baseado na necessidade de proteger as pessoas, independente de qualquer definição de grupo, mas que de alguma forma, tinham sido afetadas por um evento político ou social" (CARNEIRO, 2005, p. 2).

Já, segundo Hathaway, a implementação do Instituto do Refúgio deu-se em três momentos, os quais ele define de acordo com as abordagens jurídica, social e individualista. Sua proposta divide a perspectiva de grupo 
étnico ou nacional em duas abordagens: jurídica e social. Utilizar-se-á, portanto, a proposta de Hathaway por ser mais específica quanto aos grupos de pessoas perseguidas em seus estados de origem, pois, na fase jurídica, tais grupos recebem um reconhecimento jurídico e, na fase social, assistência internacional, principalmente aos perseguidos pelo Nazismo (HATHAWAY, 1991).

Portanto, conforme Hathaway, a instituição do refúgio deu-se por meio de três fases: abordagem jurídica de 1920-1935, caracterizada pelo reconhecimento com base no pertencimento do indivíduo a determinado grupo que necessitasse proteção; abordagem social de 19351939, caracterizada por prover assistência internacional para determinados grupos de refugiados em decorrência de acontecimentos políticos e sociais, principalmente relacionados ao Nazismo; abordagem individualista de 1938-1950, caracterizada pelo exame dos méritos do caso de cada solicitante de asilo (HATHAWAY, 1991).

\subsection{Perspectiva coletiva, de grupo étnico ou nacio- nal}

Essa perspectiva compreende o período de 1921 a 1939, quando os refugiados eram definidos coletivamente por serem parte de determinado grupo étnico ou nacional. Como já visto, Hathaway divide a perspectiva coletiva, em abordagem jurídica e abordagem social, as quais serão expostas nos próximos dois itens.

\subsubsection{Abordagem jurídica (1920-1935)}

A aparição dos refugiados como fenômeno de massa teve lugar no final da Primeira Guerra Mundial, com as quedas dos impérios russo, austro-húngaro e otomano e a nova ordem criada pelos tratados de paz que alteraram profundamente as bases territoriais da Europa centro-oriental (AGAMBEN, 1996).

Segundo Arendt, a Primeira Guerra

foi uma explosão que dilacerou irremediavelmente a comunidade dos países europeus, como nenhuma outra guerra foi capaz, fazendo com que a inflação, desemprego e guerras civis sobreviessem e se alastrassem durante os seguintes anos de 'paz agitada', que culminaram na migração de densos contingentes humanos que não eram bem-vindos e não podiam ser assimilados em parte alguma. Uma vez fora do país de origem, permaneciam sem lar; quando deixavam o seu Estado, tornavam-se apátridas; quando perdiam os seus direitos humanos, perdiam todos os direitos: eram o refugo da terra (ARENDT, 1989, p. 300).
O término da Primeira Guerra Mundial, no entanto, modificou em escala numérica inédita o padrão de pessoas que não eram bem-vindas a lugar algum e que não podiam ser assimiladas por parte alguma. Como observa Arendt, essas pessoas se converteram no "refugo da terra", pois quando perderam seus lares, sua cidadania e seus direitos se viram expulsos do seu país. Em pouco tempo, foram deslocados de seus países 1.500.000 russos brancos $^{4}, 700.000$ armênios, 500.000 búlgaros, 1.000 .000 de gregos e milhares de alemães, húngaros e romenos. A essas massas em movimento tem-se que acrescentar a situação explosiva determinada por cerca de 30\% das populações dos novos organismos estatais criados por tratados de paz conforme o modelo do Estado-nação (por exemplo, Iugoslávia e Tchecoslováquia), que constituíam minorias que tiveram que ser tuteladas por meio de uma série de tratados internacionais, chamados Minority Treaties (AGAMBEN, 1996).

Ao final da Primeira Guerra, as potências ocidentais tentaram prover os direitos elementares das minorias étnicas que estavam ameaças em decorrência do redesenho das fronteiras nacionais por meio de uma série de Tratados de Minorias. Entretanto, com a deterioração da situação econômica global que sucedeu a recuperação do início do pós-guerra, rapidamente as minorias se tornaram culpadas de tudo. "Os governos definiram amplas categorias de pessoas como pertencentes aos Estados-nação e relegaram outras à condição de estranhos e alienígenas que ameaçavam a coesão cultural e nacional” (LOESCHER, 1993, p. 34, tradução livre). Muitos grupos minoritários nacionais foram imediatamente naturalizados pelos seus novos países, mas alguns grupos não tiveram esse privilégio.

a verdadeira importância dos tratados de minorias não está em sua aplicação prática, mas

4 Os Russos Brancos eram partidários das forças contrarrevolucionárias, durante a guerra civil russa. $\mathrm{O}$ exército branco compreendia algumas das forças russas, tanto políticas como militares, que se opuseram aos Bolcheviques após a Revolução de Outubro e lutaram contra o Exército Vermelho, assim como contra o Exército Verde nacionalista e o Exército Negro anarquista durante a Guerra Civil Russa de 1918 a 1921. A denominação Branco tem dois significados. Primeiro, colocava-se em oposição aos Vermelhos - o Exército Vermelho revolucionário que apoiava o Soviete e o Comunismo. Segundo, a palavra "branco" tem associações monarquistas: historicamente, cada Czar russo era chamado solenemente de czar branco, e o ideal monarquista durante a guerra civil era conhecido como a ideia branca (REIS FILHO et al, 2000). 
no fato de que eram garantidos por uma entidade internacional, a Liga das Nações. Minorias haviam existido antes, mas a minoria como instituição permanente, o reconhecido de que milhões de pessoas viviam fora da proteção legal normal e normativa, necessitando de uma garantia adicional dos seus direitos elementares por parte de uma entidade externa, e a admissão de que este estado de coisas não era temporário, mas que os tratados eram necessários para criar um modus vivendi duradouro (ARENDT, 1989, p. 308).

O caso dos refugiados russos deve ser, ainda, salientado por outro aspecto: o número de apátridas viu-se multiplicado por uma prática política ${ }^{5}$, fruto de atos do Estado no exercício da competência soberana em matéria de imigração, naturalização e nacionalidade. A desnaturalização em massa por motivos políticos foi caminho inaugurado pelo governo russo ${ }^{6}$ pelos decretos de 28 de outubro e 15 de dezembro de 1921, os quais retiravam a nacionalidade russa daqueles que se encontravam no exterior há mais de 5 anos e, até 22 de junho de 1922, não houvessem obtido o passaporte das novas autoridades ou, ainda, houvessem abandonado a Rússia depois da revolução, em razão de sua discordância com o regime que passou a vigorar (ANDRADE, 1996). Portanto, antes de se tornarem refugiados, foram, em um primeiro momento, apátridas.

Em 1921, a Liga das Nações, juntamente com o Comitê Internacional da Cruz Vermelha ${ }^{7} / 8$, produziu a primeira organização oficial para a proteção de refugiados, o Alto Comissariado para Refugiados Russos (1921-1930), com o objetivo de socorrer os quase 2

5 A partir da Primeira Guerra Mundial muitos Estados europeus começaram a introduzir leis de desnaturalização dos seus próprios cidadãos como, por exemplo, a França, em 1915, que promulgou lei de desnaturalização para os cidadãos naturalizados de origem "inimiga”; em 1921 a URSS, que passou a adotar tal medida em razão de sua discordância com o regime que passou a viger na Rússia foram desnacionalizados; em 1922, a Bélgica revogou a naturalização dos cidadãos que haviam cometidos atos antinacionais durante a guerra (AGAMBEN, 1996).

6 Vale recordar aqui que a União das Reúblicas Socialistas soviéticas (URSS) foi constituída tão somente em 6 de julho de 1923 (FISCHEL DE ANDRADE, 1996).

Doravante, Cruz Vermelha.

8 O Comitê Internacional da Cruz Vermelha é uma organização internacionalmente conhecida por sua atuação em situações de guerra. Ao ajudar vítimas de guerra, a atuação da Cruz Vermelha recai sobre o domínio do Direito Internacional Humanitário, mas, como muitas vezes os conflitos bélicos geram refugiados, essa organização acaba, na prática, por assisti-los (JUBILUT, 2007, p. 74). milhões de russos que foram obrigados a deixar seu país após a Revolução Russa (JUBILUT, 2007). A função desse organismo era definir a situação jurídica dos refugiados, repatriá-los ou levá-los a assentamentos. Esse Comissariado era coordenado pelo Delegado do Governo da Noruega na Sociedade das Nações, Fridtojf Nansen ${ }^{9}$, que conseguiu sensibilizar a comunidade internacional a fim de tratar de encontrar uma solução permanente para o problema dos refugiados.

Inicialmente, Nansen estava envolvido com os problemas práticos dos refugiados russos e, em particular, com os problemas dos refugiados que necessitavam viajar. Entretanto, esses eram problemas extremamente complexos e não podiam ser resolvidos rapidamente. A maioria simplesmente não podia retornar para casa, tampouco assentar-se espontaneamente na Europa, nem viajar para a América do Norte ou algum outro destino ultramarino de imigração (LOESCHER, 1993).

Em 5 de julho de 1922, sob os auspícios do Alto Comissariado para Refugiados Russos, foi ratificado por 52 países, em Genebra, o Ajuste Relativo à Expedição de Certificados de Identidade para os Refugiados Russos (LEAGUE OF NATIONS, 1922). Esse acordo não definiu de forma definitiva o que deveria se entender por refugiado russo, porém instituiu o Certificado de Identidade para Refugiados Russos, idealizado pelo comissário Fridtjof Nansen, que ficou conhecido como Passaporte Nansen destinado a dar aos refugiados russos um status jurídico, identificá-los e permitir aos que se refugiavam viajar sobre o território dos países que os reconheciam e retornar ao país que havia expedido o documento. Foi um primeiro passo para dar aos refugiados a possibilidade de começar uma nova vida e radicar-se.

A equipe do Alto Comissariado visou protegêlos providenciando serviços consulares e intervenções diplomáticas com os governos hospedeiros que haviam ameaçado sua expulsão e deportação. Finalmente,

9 O Dr. Fridtjof Nansen (1861-1930), além de delegado da Noruega na Liga das Nações, era cientista e explorador, tendo-se aventurado a atravessar a Groenlândia, em 1888, alcançando, poucos anos depois, o ponto mais próximo do Polo Norte. Em razão do seu profícuo trabalho humanitário, foi reconhecido com o Prêmio Nobel da Paz, em 1923, e o ACNUR condecora, até os dias de hoje, as pessoas que atuam a favor da proteção aos refugiados com a "Medalha Nansen" (LOESCHER, 1993). 
através de hábil diplomacia, Nansen resolveu o problema diretamente ao persuadir cinquenta e um governos a reconhecer os documentos chamados "Passaportes Nansen" para russos apátridas. Com esses documentos, não apenas os refugiados russos, mas também outros puderam mover-se legalmente de áreas onde suas estadias eram temporárias e frequentemente ilegais para áreas mais hospitaleiras na Europa e em outros lugares (LOESCHER, 1993).

Em 31 de Maio de 1924, o mandato do Alto Comissariado para os Refugiados Russos foi ampliado para proteger os armênios, vítimas do primeiro grande genocídio do século $\mathrm{XX}^{10}$. Por intercessão do Dr. Nansen, nesse ano, foi assinado entre 35 nações, inclusive o Brasil, o Plano Relativo à Expedição dos Certificados de Identidade para os Refugiados Armênios, que objetivava estender o sistema de proteção jurídica para os $300 \mathrm{mil}$ armênios que fugiam do genocídio e que se encontravam espalhados pela Síria, Iraque, Chipre, Palestina, Grécia, Bulgária e por outros países europeus. Desde então, os

10 O genocídio armênio é considerado o primeiro grande genocídio do século XX e se constituiu na deportação e massacre de 1,5 milhão de armênios pelo Império Otomano, entre 1915 e 1923. Seus antecedentes remontam o século XI, quando uma série de invasões, migrações, deportações e massacres, reduziu os armênios, povo cristão, a uma população minoritária em seu território original, forçando inúmeros mercadores, personalidades religiosas e intelectuais a migrarem para a Índia, Rússia, Polônia e outros países do Leste Europeu. No século XV, os armênios restantes sobreviviam como camponeses, sob o domínio do Império Otomano, enquanto muitos outros eram artesãos e mercadores em Constantinopla, Esmirna, ou outras cidades menores. No século XIX, a ideia de independência voltou a ganhar força, mas no ano de 1909, o Império Otomano iniciou um massacre que fez vinte mil vítimas. Na Primeira Guerra Mundial, o Império Otomano estava em guerra com a Tríplice Entente, composta por Grã-Bretanha, Rússia e França e, como em todos os países beligerantes, cidadãos do sexo masculino foram convocados em massa. No caso otomano, por se tratar de um império com várias minorias nacionais hostis a Istambul, o recrutamento não foi bem recebido por muitas dessas minorias. Os armênios se rebelaram contra a guerra e contra a interminável opressão otomana. Foram reprimidos com um genocídio em massa; de acordo com fontes armênias, cerca de 1,5 milhão de pessoas foram humilhadas, deportadas, torturadas, estupradas e/ou mortas. Em 15 de abril de 1915 , teve início uma operação programada de extermínio do povo armênio conduzida pelo governo dos Jovens Turcos, com prisões de líderes intelectuais e políticos, seguida pela deportação da população e da marcha pelo deserto da Mesopotâmia, onde brutalmente foram assassinados cerca de 1,5 milhão de uma população total de aproximadamente dois milhões de armênios (AKÇAM, 2004). armênios tiveram o direito de portar o Passaporte Nansen e passaram a ser conhecidos, juntamente com os russos, como refugiados Nansen (FISCHEL DE ANDRADE, 1996).

Em 12 de maio de 1926, foi celebrado o Arrangement relating to the issue of identity certificates to Russian and Armenian refugees para definir quem eram os refugiados russos e armênios (LEAGUE OF NATIONS, 1926).

Como já descrito, as primeiras definições do conceito de refugiado centravam-se em dar uma definição jurídica a determinado grupo étnico ou nacional à qual o refugiado pertencia, como por exemplo as definições adotadas pelo acordo de 1926:

Russo: Qualquer pessoa com origem russa a qual não goze ou a qual não tenha mais gozado da proteção do Governo da União das Repúblicas Socialistas Soviéticas e a qual não tenha adquirido outra nacionalidade.

Armênios: Qualquer pessoa com origem armênia anteriormente súditos do Império Otomano a qual não goze ou a qual não tenha mais gozado da proteção do Governo da República da Turquia e a qual não tenha adquirido outra nacionalidade (LEAGUE OF NATIONS, 1926, tradução livre).

Ademais, em 1928, começa a constituir-se, em âmbito internacional, o princípio do non-refoulment ${ }^{11}$, por meio do Arrangements relating to the legal status of Russian and Armenian refugees of 30 June 1928, no qual, pela primeira vez, esse princípio aparece em um instrumento jurídico de Direito internacional, ainda que de forma incipiente (LEAGUE OF NATIONS, 1928). Para Fischel de Andrade, trata-se do "embrião do princípio de non-refoulement", pois recomendava que a expulsão fosse suspensa ou não realizada caso o refugiado não reunisse condições legais para adentrar no país para onde se daria a condução (FISCHEL DE ANDRADE, 1996, p. 54).

Em 1930, Nansen morre e, durante os próximos 10 anos, o regime internacional dos refugiados que ele havia estabelecido e liderado tornou-se totalmente incapaz de lidar com os problemas dos refugiados

11 Principio fundamental do direito dos refugiados, em virtude do qual nenhum Estado poderá devolver o indivíduo ao país de onde ele está fugindo, pondo de nenhum modo o refugiado nas fronteiras do território de onde sua vida ou liberdade estejam ameaçadas. Posteriormente, na Convenção de 1951, esse principio passou a ser positivado. 
judeus (LOESCHER, 1993). Ainda em 1930, as responsabilidades envolvendo a proteção dos refugiados foram colocadas sob a égide do Secretariado da Liga das Nações, enquanto a responsabilidade pela administração dos demais programas de assistência foi transferida para uma agência que se tornou conhecida como o Escritório Nansen (1930-1938).

Em 1933, abriram-se as assinaturas para a Convenção Relativa ao Estatuto Internacional dos Refugiados, elaborada pelo Escritório Nansen. Essa convenção visou ampliar praticas de repatriação e conceder aos refugiados russos e armênios direitos nos seus países de asilo (LOESCHER, 1993).

Alguns dos aspectos mais relevantes da Convenção diziam respeito a questões de ordem administrativa, situação jurídica e condições para o trabalho. Segundo Loescher, "uma série de direitos que os refugiados receberam foram especificados, incluindo educação, emprego no país receptor e documentos de viagem" (LOESCHER, 1993, p. 37, tradução livre).

No tocante ao conceito de refugiado, o artigo $1^{\circ}$ regrava que

\begin{abstract}
a presente Convenção é aplicável aos refugiados russos, armênios e assimilados, tal como definidos pelos Ajustes de 12 de maio de 1926 e de 30 de junho de 1928, sujeitos às modificações ou ampliações que cada Estado Contratante pode introduzir nesta definição no momento da assinatura ou da adesão (LEAGUE OF NATIONS, 1933, tradução livre).
\end{abstract}

O grande legado da Convenção de 1933 dividese em dois pontos que merecem destaque: primeiro, a continuidade dada à essência de proteção aos refugiados, ou seja, não houve qualquer restrição na qualificação dos refugiados, pois a utilização da expressão "assimilados" abriu possibilidades maiores do que o até então concebido; segundo, a ampliação do âmbito e solidificação do princípio de non-refoulement, pois, no art. $3^{\circ}$ dessa Convenção, encontra-se a obrigação de não repelir em qualquer hipótese, aqueles que, porventura, necessitem de proteção internacional (LEAGUE OF NATIONS, 1933).

\subsubsection{Abordagem social (1935-1939)}

A situação dos refugiados judeus alemães e o êxodo promovido em razão da política atroz e antissemita adotada pelo governo nazista de Adolf Hitler, que assumiu o poder em 30 de janeiro de 1933, maciças do regime nazista ${ }^{12}$, iniciadas pela lei de 14 de julho de 1933, os judeus passaram a ser perseguidos em toda a Alemanha, se tornando cidadãos de segunda classe e perdendo todos os seus direitos, além disso, as desnaturalizações alcançaram um grande número de judeus e imigrados políticos residentes fora do Reich (LAFER, 1988; AGAMBEN, 1996).

Devido à gravidade da situação, em 4 de julho de 1936, por meio de um acordo, foi criado o Alto Comissariado para os Refugiados da Alemanha (Judeus e outros), ${ }^{13}$ o qual defendia que os refugiados não deveriam ser devolvidos à fronteira do Reich (LEAGUE OF NATIONS, 1936). Desde então, entra em cena um novo critério definidor, que tende a substituir àquele tradicional da origem nacional: a perseguição.

Dando seguimento a esse acordo, foi redigida a Convenção Relativa aos Refugiados Provenientes da Alemanha, de 10 de fevereiro de 1938, que igualou a situação do apátrida à do refugiado e excluiu do rol de proteção aquelas pessoas que deixavam seu país por conveniência (LEAGUE OF NATIONS, 1938). Tal convenção estabeleceu a proibição da expulsão ou devolução dos refugiados ao território alemão, reiterando o princípio de non-refoulement, salvo "no caso em que a segurança nacional ou a ordem pública o façam necessário" (FERNANDEZ, 2004, p. 93, tradução livre).

A Convenção que foi promulgada em 1938, em benefício dos refugiados provenientes da Alemanha, foi estendida em 1939, por meio de um Protocolo Adicional, às pessoas provenientes da Áustria. Segundo esse protocolo, a expressão "refugiados provenientes da Alemanha" presente no Artigo I do Acordo de 1936 e no Artigo I da Convenção de 1938 refere-se a pessoas

12 "A perda da condição nacional por mudança ou incompatibilidade, fruto de atos deliberados dos indivíduos, não é o caso daqueles que se convertem coletivamente em apátridas, não pelo que fizeram ou pensaram, mas pura e simplesmente porque nasceram ou eram membros de uma classe, de uma raça ou de um grupo nacional. Estas desnacionalizações maciças pronunciadas pelos regimes soviético e nazista, independentemente da conduta específica das pessoas e no contexto das restrições à livre circulação das pessoas que caracterizaram o primeiro pós-guerra, fizeram com que o problema dos apátridas de torna-se um problema inédito" (LAFER, 1988, p. 144).

13 O problema dos refugiados provenientes da Alemanha não se limitava aos Judeus, pois também eram perseguidos pelos nazistas os inimigos políticos (mesmo arianos), os ciganos, os homossexuais, etc. (LOESCHER, 1993). 
que, tendo possuído a nacionalidade austríaca e não possuindo qualquer outra nacionalidade, senão a alemã, provem não gozar, de fato e de direito, da proteção do governo da Alemanha (LEAGUE OF NATIONS, 1939).

Embora nenhuma dessas Convenções tenha recebido assinatura de mais de oito nações, elas foram significantes como os primeiros esforços internacionais para elaborar um corpo de tratados destinados a proporcionar proteção aos refugiados. Apesar do texto dessas convenções ter limitado intencionalmente beneficiar estritamente os grupos nacionais definidos e promovido somente uma proteção mínima para os membros desses grupos, eles foram um degrau em direção à formulação de leis internacionais e instituições mais permanentes (LOESCHER, 1993, 36-37, tradução livre).

Em 1938, a Noruega propôs a unificação dos organismos que tratavam dos refugiados, mediante a criação de um único órgão internacional com essa responsabilidade. Sendo assim, em dezembro de 1938, deu-se a extinção do Escritório Nansen e do Alto Comissariado para os refugiados da Alemanha, ensejando a criação e a regulamentação do Alto Comissariado da Liga das Nações para Refugiados (ACLNR), com sede em Londres, cujas atividades iniciaram-se em $1^{\circ}$ de janeiro de 1939 (BARBOSA; HORA, 2006, p. 16).

\subsection{Perspectiva individualista (1938-1950)}

A partir de 1938, a ênfase das definições jurídicas do conceito de refugiado desloca-se para o indivíduo e seu caso pessoal (elemento subjetivo), o que cria a necessidade do estabelecimento de um procedimento de análise. $\mathrm{O}$ aparecimento do segundo critério, mais enfocado na realidade da experiência da perseguição, foi definitivamente influenciado pela ascensão do Nazismo na Alemanha, em 1933, que imediatamente desencadeou perseguições em massa.

este critério ampliou a possibilidade do refugio a todas as pessoas que haviam de fato, e não apenas de jure, perdido a proteção de seu estado de origem, não apenas em base grupal ou jurídica. A perseguição nazista atingiu pessoas definidas em base a razões políticas, (comunistas, socialdemocratas e sindicalistas) e étnicas; judeus retratados como os grandes vilões, ciganos, eslavos e michling (alemães com alguma ascendência judaica). Gradativamente o Nazismo estabeleceu todo um sistema de violência sistemática, onde opositores, líderes, homossexuais, artistas, cientistas e não-ários em geral foram implacavelmente perseguidos e exterminados (CARNEIRO, 2005, p. 2).
Antes de a Segunda Guerra Mundial chegar ao fim, as movimentações de pessoas na Europa já vinham causando preocupação aos países aliados ${ }^{14}$. Em consequência disso, no dia 9 de novembro de 1943, na Casa Branca, em Washington, conclui-se o Acordo de Criação da Administração das Nações Unidas para o Auxílio e Restabelecimento (UNRRA) ${ }^{15}$.

Fischel de Andrade destaca que, quando a UNRRA foi criada, não deveria somente assistir refugiados, mas também coordenar os programas de repatriação, "o que a tornou uma organização pioneira, posto ter sido, na linha dos organismos internacionais até então existentes, a primeira a ser responsável pela assistência e pela repatriação dos refugiados" (FISCHEL DE ANDRADE, 1996, p. 142). Dotada de um amplo mandato, assistia todas as pessoas que eram forçadas pela guerra a abandonar suas casas e colaborava no socorro e na reconstrução das regiões devastadas, assistindo, então, não somente os refugiados (SMERALDI, 2005).

Tratava-se de um organismo internacional temporário, ao qual aderiram 44 Estados, e tinha como objetivo prover auxílio e reabilitação às zonas devastadas, bem como prestar socorro e assistência às pessoas deslocadas pela guerra e aos refugiados (FISCHEL DE ANDRADE, 1996).

Em 1944 e 1945, a UNRRA proporcionou assistência emergencial temporária para milhões de pessoas deslocadas que caíram nas mãos dos aliados, seguindo o padrão estabelecido no intervalo entre as Guerras. A UNRRA, entretanto, não foi estritamente uma organização para refugiados: ela ajudou todos que foram deslocados pela guerra $\mathrm{e}$ em alguns casos os refugiados com temores políticos (LOESCHER, 1993, p. 43, tradução livre).

Segundo Hathaway, a concepção mais individualizada para o status de refugiado assinalou uma mudança do Direito dos Refugiados, baseada em uma preocupação humanitária generalizada, que visava promover uma proteção em bloco, para um foco mais seletivo, no sentido de assistir pessoas cujos direitos tivessem sido violados (HATHAWAY, 1990).

14 EUA, Reino Unido, França e URSS.

15 Utilizar-se-á à sigla UNRRA, referente ao nome em inglês: United Nations Relief and Rehabilitation Administration. A UNRRA foi a primeira organização internacional a incorporar a palavra 'Nações Unidas' em seu título e foi criada cerca de dois anos antes do estabelecimento da Organização das Nações Unidas (FISCHEL DE ANDRADE, 1996, p. 135136). 
O fim da Segunda Guerra trouxe ainda mais problemas relacionados à questão dos refugiados. Os "novos refugiados" criados pelos dois grandes conflitos não fugiam de perseguições ligadas às suas escolhas políticas. Segundo Arendt, esses

\begin{abstract}
novos refugiados não eram perseguidos por algo que tivessem feito ou pensado, mas sim em virtude daquilo que imutavelmente eram nascidos na raça errada (como no caso dos judeus na Alemanha), ou na classe errada (como no caso dos aristocratas na Rússia), ou convocados pelo governo errado (como no caso dos soldados do Exército Republicano espanhol) (ARENDT, 1989, p. 328).
\end{abstract}

E o que se viu foi a necessidade de criar um organismo que se ocupasse em buscar soluções para os problemas relacionados às milhares de pessoas sem lar, sem país e sem nacionalidade, refugiados e apátridas que se espalhavam por toda Europa. Em 1945, existiam cerca de 11 milhões de deslocados pela Europa, situação parcialmente controlada através do Acordo de Criação da Administração das Nações Unidas para o Controle e Reconstrução, o qual repatriou cerca de oito milhões de pessoas. Entretanto, outros milhões ainda não tinham onde morar (ACNUR, 2005a, p. 6).

Em junho de 1945, constituiu-se a Organização das Nações Unidas (ONU), cujos objetivos principais eram assegurar a paz e a segurança internacionais, bem como promover a cooperação internacional a fim de atingir o desenvolvimento socioeconômico e o respeito aos direitos humanos. Como se pode ver, a Segunda Guerra Mundial marcou uma nova concepção de direitos humanos, resultado das atrocidades praticadas pelo holocausto, o que ensejou uma preocupação internacional com a dignidade humana. Nesse contexto, em 1948, a ONU elaborou a Declaração Universal dos Direitos Humanos, um instrumento internacional que consagrou os direitos humanos e constituiu um código de ação comum aos Estados (PIOVESAN, 2004).

Em consequência da sua falha na prevenção da Segunda Guerra Mundial, a Liga das Nações foi desconstituída juntamente com o Alto Comissariado da Liga das Nações para Refugiados (ACNUR, 2005a). Segundo Smeraldi, o mandato da ACLNR "conclui-se em 31 de dezembro de 1946, logo após as atividades da Liga das Nações cessarem, que ocorreu por meio da deliberação da Assembleia da Liga das Nações de 18 de abril de 1946" (SMERALDI, 2005, p. 10, tradução livre).

Antes mesmo de cessarem as atividades da
UNRRA, a problemática dos refugiados e deslocados foi incluída na primeira sessão da Assembleia Geral da ONU, realizada entre 10 de janeiro e 14 de fevereiro de 1946, em Londres. A Assembleia Geral adotou, no dia 12 de fevereiro, uma Resolução que recomendava o estabelecimento de um Comitê Especial para preparar um relatório, a ser examinado na primeira sessão do Conselho Econômico e Social (ECOSOC) e na segunda parte da primeira Sessão da Assembleia Geral, a ser realizada no fim do segundo semestre daquele mesmo ano, pois considerava de urgência imediata a busca de solução para o problema dos refugiados e dos deslocados, "além da necessidade imperiosa de distingui-los dos criminosos de guerra, espiões e traidores" (FISCHEL DE ANDRADE, 2005, p. 64).

A segunda parte da primeira sessão da Assembleia Geral realizou-se em Nova York, de 23 de setembro a 15 de dezembro de 1946. No último dia da Sessão da Assembleia, pela Resolução 62(I), foi votada a Constituição da Organização Internacional para os Refugiados ${ }^{16}$. A deliberação da Constituição contou com 18 abstenções, 30 votos a favor e 5 contra (SANTIAGO, 1989). Para Andrade, as abstenções refletiam o desinteresse em se tratar dos problemas dos refugiados; enquanto os votos contrários, o desejo dos países socialistas de manter essa questão fora da agenda internacional. Segundo ele,

devido à premência de se centralizar o trabalho de proteção e de assistência aos refugiados e aos deslocados, sob a égide das Nações Unidas, e de se manter esse tema na Agenda internacional, conclui-se, no mesmo dia em que se aprovou a Constituição da Organização Internacional para os Refugiados, o Acordo sobre Medidas Provisórias a serem tomadas concernentes aos Refugiados e Deslocados (FISCHEL DE ANDRADE, 1996, p. 142).

O Acordo de 1946 estabelecia que a Comissão Preparatória da IRO deveria dar continuidade aos trabalhos referentes aos refugiados e deslocados durante o período do encerramento das atividades da UNRRA, previsto para meados de 1947, até a existência oficial da Organização Internacional para os Refugiados.

A Constituição da IRO, porém, entrou em vigor somente em 20 de agosto de 1948, tendo como consequência a extinção da Comissão Preparatória (GOODWIN-GILL, 1996). A substituição da Comissão

16 Doravante utilizar-se-á a sigla IRO, referente ao nome em inglês: International Refugee Organization. 
pela IRO teve importante efeito financeiro na execução dos trabalhos em prol dos refugiados, devido ao fato que "durante a fase inicial, a Comissão Preparatória recebeu tão-somente adiantamentos posteriormente dedutíveis das colaborações, que seriam devidas quando a IRO entrasse em pleno funcionamento" (FISCHEL DE ANDRADE, 2005, p. 66).

Quando o mundo estava atônito diante dos crimes cometidos pelo nazismo, nasceu a IRO cujo estatuto se conformou aos fins e princípios da Carta das Nações Unidas e introduziu uma nova definição de refugiado, ainda que ancorada na concepção clássica dos acordos internacionais dos anos 30. Ademais, o texto constitucional trazia a seguinte definição de refugiado, que se aplicava

1. [...] a toda pessoa que partiu, ou que esteja fora, de seu país de nacionalidade, ou no qual tinha sua residência habitual, ou a quem, tenha ou não retido sua nacionalidade, pertença a uma das seguintes categorias:

(a) vítimas dos regimes nazista ou fascista ou de regimes que tomaram parte ao lado destes na Segunda Guerra Mundial, ou de regimes traidores ou similares que os auxiliaram contra as Nações Unidas, tenham, ou não, gozado do status internacional de refugiado;

(b) republicanos espanhóis e outras vítimas do regime falangista na Espanha tenham, ou não, gozado do status internacional de refugiado;

(c) pessoas que foram consideradas refugiadas, antes do início da Segunda Guerra Mundial, por razões de raça, religião, nacionalidade ou opinião política.

2. [...] estiverem fora de seu país de nacionalidade, ou de residência habitual, e que, como resultado de eventos subsequentes ao início da Segunda Guerra Mundial, estejam incapazes ou indesejosas de se beneficiarem da proteção do governo do seu país de nacionalidade ou nacionalidade pretérita.

3. [...] tendo residido na Alemanha ou na Áustria, e sendo de origem judia ou estrangeiros ou apátridas, foram vítimas da perseguição nazista e detidos, ou foram obrigados a fugir, e foram subsequentemente retornados a um daqueles países como resultado da ação inimiga, ou de circunstâncias de guerra, e ainda não foram definitivamente neles assentados.

4. [...] sejam órfãos de guerra ou cujos parentes desapareceram, e que estejam fora de seus países de nacionalidade. (UNITED NATIONS GENERAL ASSEMBLY, 1946)
Ao contrário das definições anteriores pautadas numa perspectiva coletivista, que caracterizavam o refugiado a partir de sua origem ou filiação a um determinado grupo étnico, racial ou religioso, a Constituição da IRO traz uma definição de refugiado mais ampla e individualista, pois demandava a análise da situação de cada indivíduo (FISCHEL DE ANDRADE, 1996). Ela estabeleceu um novo sistema de elegibilidade individual que transcende o pertencimento a uma categoria específica coletivamente determinada, fazendo valer a questão individual e a história pessoal (MALENA, 2008, p. 21).

Paralelamente ao encerramento previsto da $\mathrm{IRO}^{17}$, já se estudava a criação de seu sucessor e vislumbrava-se como principal desafio a busca de critérios que fossem universalmente acatados. Assim, em 03 de dezembro de 1949, começou a tomar forma o Alto Comissariado das Nações Unidas para Refugiados (ACNUR), cujo Estatuto foi aprovado em 14 de dezembro de 1950 (BARBOSA; HORA, 2006).

A evolução do Direito Internacional dos refugiados intensificou-se entre 1938 e1950, em particular no que dizia respeito à determinação do status de refugiado. Não era mais suficiente ser membro de um grupo de deslocados ou apátridas, era requerida uma análise das razões de cada solicitante para o reconhecimento como refugiado.

\section{Convenção de 1951 e Protocolo de 1967}

Assim, o sistema jurídico para os refugiados tem como marco a Resolução 319 A (IV) da Assembleia-Geral da ONU, de 3 de dezembro de 1949 cujo objeto foi a criação do Alto Comissionado das Nações Unidas para os Refugiados (ACNUR) (UNITED NATIONS GENERAL ASSEMBLY, 1949).

Seu Estatuto encontra-se anexado à Resolução 428 (V) da Assembleia Geral n. 428 da ONU, em de 14 de dezembro de 1950. O ACNUR teve o início de suas atividades em $1^{\circ}$ de janeiro de 1951, com a tarefa fundamental de conceder proteção jurídica internacional aos refugiados e adotar a Convenção de Genebra de 1951, relativa ao Estatuto dos Refugiados, emendada pelo

17 As atividades da IRO tiveram fim em 28 de fevereiro de 1952, quando já tinha sido criado o atual ACNUR (BONAMINI, 2003-2004, p. 32) 
Protocolo de Nova Iorque de 1967 (UNITED NATIONS GENERAL ASSEMBLY, 1950). Esses instrumentos jurídicos proporcionaram uma estrutura formal para responder às necessidades gerais dos refugiados, estabelecendo normas para protegê-los no âmbito do Direito Internacional (FISCHEL DE ANDRADE, 2006).

O ACNUR foi criado para que os refugiados recebessem a proteção que lhes era devida e não recebeu poderes coercitivos que pudessem determinar o cumprimento de certas ações e iniciativas por parte dos Estados em prol da proteção dos refugiados, todavia representou um passo nessa direção. A missão do ACNUR foi e ainda é garantir o bem-estar dos refugiados. Para isso, o Alto Comissariado busca, até os dias de hoje, assegurar a todos o direito de procurar asilo e encontrar refúgio seguro em outro Estado, ou voltar voluntariamente ao seu país.

Já as origens da Convenção relativa ao Estatuto dos Refugiados ${ }^{18}$ podem ser encontradas nos trabalhos do Ad Hoc Committee on Refugees and Stateless Persons, nomeado pelo ECOSOC pela Resolução 248 (IX), de 8 de agosto de 1949, com o mandato de para considerar a conveniência de preparar uma Convenção relacionada ao status internacional dos refugiados e apátridas, e em caso afirmativo, para preparar o texto dessa convenção" (LAUTERPACHT; BETHLEHEM, 2003, p. 98-99, tradução livre).

o sofrimento inenarrável vivenciado por milhões de criaturas humanas que sobreviveram à grande catástrofe do século XX, a Segunda Guerra Mundial (que ceifou a vida de mais de quarenta milhões de pessoas), levou as Nações Unidas a elaborar uma das mais importantes convenções internacionais, que regula a situação jurídica dos refugiados (DOLINGER, 1996, p. 209).

A Conferência de Plenipotenciários, realizada em Genebra entre os dias 2 e 25 de julho de 1951, objetivava completar a minuta da Convenção e assiná-la, e contou com a participação de delegações de 26 países, além de representantes do ACNUR, OIR e OIT, sem direito a voto, e da Cáritas Internationalis, do Comitê Internacional da Cruz Vermelha e de diversas ONGs, como observadores ${ }^{19}$.

18 Doravante, Convenção de 1951, conforme o usual nos textos do ACNUR.

19 Os 26 países que participaram da Conferência foram os seguintes: Austrália, Áustria, Bélgica, Brasil, Canadá, Colômbia, Dinamarca, Egito, Estados Unidos, França, Grécia, Holanda, Iraque, Israel, Itália, Iugoslávia, Luxemburgo, Mônaco, No-
A Conferência foi marcada por duas correntes de pensamento distintas: a primeira entendia que a Convenção consistia num instrumento geral e deveria ser aplicável a todos os refugiados, independentemente de sua origem; a outra, que a Convenção tinha seu alcance limitado e deveria se aplicar somente aos refugiados originados de países europeus (ACNUR, 2013a). Os países que sustentavam a primeira corrente foram chamados de "universalistas" ${ }^{20}$ e os segundos de "europeístas".21

A conferência foi finalizada em 28 de julho de 1951 e a Convenção Relativa ao Estatuto dos Refugiados foi assinada por 12 países $^{22}$, porém só entrou em vigor em 22 de abril de 1954 (LAUTERPACHT; BETHLEHEM, 2003).

Desde então a Convenção é considerada o eixo fundador do Direito Internacional dos Refugiados. Ela define quem é refugiado no capítulo 3 e padroniza os tratamentos para aqueles abrigados sob essa definição nos capítulos 5 e 6 . A Convenção de 1951 representa um marco na emergência de uma vontade global em encaminhar os problemas de deslocamentos forçados (ACNUR, 2005a).

$\mathrm{O}$ artigo $1^{\circ}$. A., $\S 2^{\circ}$, da Convenção de 51 traz o conceito de Refugiado, conforme segue:

Para fins da presente Convenção, o termo "refugiado" se aplicará a qualquer pessoa que, em consequência dos acontecimentos ocorridos antes de $1^{\circ}$ de janeiro de 1951 e temendo ser perseguida por motivos de raça, religião, nacionalidade, grupo social ou opinióes políticas, encontra-se fora do país de sua nacionalidade e que não pode ou, em virtude desse temor, não quer valer-se da proteção desse país, ou que, se não tem nacionalidade encontra-se fora do país

ruega, Reino Unido e Irlanda do Norte, República Federal da Alemanha, Suécia, Suíça (cuja delegação também representou Liechtenstein), Turquia e Venezuela. Além destes, Cuba e Irã foram representados por observadores (ACNUR, 2013a).

20 "Compreendia os representantes do Reino Unido, do Egito, da Iugoslávia, do Canadá, da Bélgica, dentre outros. O representante do Reino Unido foi quem mais defendeu a concepção universalista, pretendendo uma definição de refugiado o mais abrangente possível, sem qualquer tipo de limitação" (MOREIRA, 2006, p. 61).

21 "Compunha-se pelos representantes da França, dos Estados Unidos, da Itália, da Austrália, dentre outros [...]. Uma das justificativas utilizadas por esses países consistia no fato de que já acolhiam um grande número de refugiados e, caso a definição fosse muito ampla, não teriam condições financeiras de abrigar um contingente maior deles" (MOREIRA, 2006, p. 61).

22 Os 12 países que assinaram a Convenção em julho de 1951 foram: Áustria, Bélgica, Colômbia, Dinamarca, Holanda, Iugoslávia, Liechtenstein, Luxemburgo, Noruega, Reino Unido, Suécia e Suíça (ACNUR, 2013c). 
no qual tinha sua residência habitual em consequência de tais acontecimentos, não pode ou, devido ao referido temor, não quer voltar a ele (ACNUR, 2013b).

A Convenção aponta quatro elementos definidores da condição de refugiado: o refugiado deve estar fora do seu país de origem; a falta de vontade ou incapacidade do Estado de origem de proporcionar proteção ou de facilitar o retorno; a causa dessa incapacidade ou falta de vontade atribuída a um fundado temor de perseguição que provoca o deslocamento; e, enfim, a perseguição é temida por razões de raça, religião, nacionalidade, pertencimento a um determinado grupo social ou por opinião política (GOODWIN-GILL, 1996).

A Convenção estabelece o estatuto pessoal dos refugiados e os padrões mínimos para seu trato, incluindo um enumerado de direitos básicos. Entre esses direitos encontram-se o direito a um emprego remunerado e à assistência social, receber documentos de identidade e passaporte, além de transferir seus bens para o país onde seja admitido com o propósito de reassentar-se. Além disso, a Convenção promove o apoio à naturalização e à assimilação de refugiados, o acesso aos tribunais, à educação, à seguridade social, à habitação, e à liberdade de circulação.

Um dos pontos mais importantes da Convenção é o artigo 33, onde o principio do non-refoulement é sancionado, o qual proíbe a expulsão ou devolução forçada, "a menos que existam circunstâncias excepcionais claramente definidas e que justifiquem a adoção de tais medidas" (ACNUR, 2008, p. 19, tradução livre). O artigo citado declara que:

\footnotetext{
1. Nenhum dos Estados Contratantes expulsará ou rechaçará, de maneira alguma, um refugiado para fronteiras dos territórios em que a sua vida ou liberdade seja ameaçada em virtude da sua raça, da sua religião, da sua nacionalidade, do grupo social a que pertence ou das suas opiniões políticas.

2. O benefício da presente disposição não poderá, todavia, ser invocado por um refugiado que por motivos sérios seja considerado um perigo para a segurança do país no qual ele se encontre ou que, tendo sido condenado definitivamente por um crime ou delito particularmente grave, constitui ameaça para comunidade do referido país (ACNUR, 2013b)
}

Esse princípio está na base do conceito de refúgio e do direito de asilo, como o da Convenção, nos quais o objetivo principal é proteger o indivíduo da perseguição. "É lógico, então, que o empenho fundamental dos
Estados signatários seja não rechaçar os refugiados não somente para o país do qual fugiram, mas também até qualquer país aonde possam encontrar-se em perigo" (BONAMINI, 2003-2004).

Consoante o texto da Convenção de 51, "acontecimentos ocorridos antes de $1^{\circ}$ de janeiro de 1951" poderiam ser entendidos de duas maneiras: em primeiro lugar, como aqueles que tiveram lugar na Europa (o que foi interpretado como uma "reserva geográfica", reconhecendo-se como refugiados apenas pessoas de origem europeia); e, em segundo lugar, como aqueles que tiveram lugar na Europa ou fora dela.

Tendo em vista novos acontecimentos ocorridos no cenário internacional, como a descolonização africana, gerando novo fluxo de refugiados, o Protocolo relativo ao Estatuto dos Refugiados ${ }^{23}$ foi elaborado e submetido à Assembleia Geral da ONU em 1966. Por meio da Resolução 2198 (XXI) de 16 de dezembro de 1966, a Assembleia solicitou ao Secretário-Geral que submetesse o texto do Protocolo ao consentimento dos Estados (UNITED NATIONS GENERAL ASSEMBLY, 1966). O Protocolo foi assinado pelo presidente da AssembleiaGeral e pelo Secretário-Geral em Nova York, no dia 31 de janeiro de 1967, e entrou em vigor em 4 de outubro de 1967, após atingir seis instrumentos de adesão $0^{24}$.

O Protocolo buscou eliminar as limitações geográficas e temporais contidas na Convenção de 51, a qual estabelecia que somente seriam reconhecidos como refugiados aqueles que tivessem receio de serem perseguidos "em consequência dos acontecimentos ocorridos antes de $1^{\circ}$ de janeiro de 1951". Com o Protocolo de 67, esses termos passaram a não ser mais aplicados à definição de refugiado (MESA NACIONAL PARA LAS MIGRACIONES, 2004).

Conforme o disposto no Artigo $1^{\circ}$ do Protocolo de 1967,

$\$ 2$. Para os fins do presente Protocolo, o termo "refugiado" [...] significa qualquer pessoa que se enquadre na definição dada no artigo primeiro da Convenção, como se as palavras "em decorrência dos acontecimentos ocorridos antes de $1^{\circ}$ de janeiro de 1951 e..." e as palavras "...como consequência de tais acontecimentos” não fi-

23 Doravante, Protocolo de 1967, conforme o usual nos textos do ACNUR.

24 O primeiro deles foi depositado pelo Vaticano, seguindo-se pelos da República Centro Africana, Camarões, Gâmbia, Senegal e Suécia (ACNUR, 2013c). 
gurassem do $\$ 2$ da seção A do artigo primeiro (PROTOCOLO SOBRE O ESTATUTO DOS REFUGIADOS, 2001, p. 413).

Ainda que o Protocolo de 1967 esteja ligado à Convenção de 1951, ele conserva um caráter próprio, pois é um instrumento jurídico independente, pelo fato de que sua adesão pura e simples é suficiente para que a maior parte das disposições da Convenção de 1951 se torne aplicável aos Estados que a ele aderirem. Contudo, muitos foram os Estados que preferiram ratificar a Convenção e o Protocolo, reforçando, desse modo, a autoridade desses dois instrumentos do Direito Internacional relativos aos refugiados e os únicos de caráter universal.

\section{Considerações finais}

O fenômeno dos conflitos relacionados com divisões étnicas e sociais, violações de direitos humanos e políticas discriminatórias não é novo. Como já foi visto, no decorrer da história da humanidade muitos tiveram que abandonar os seus lares, cidades ou países, vítimas de circunstâncias que atingiam sua segurança, integridade física e psicológica ou, ainda, seus direitos humanos fundamentais. Trata-se de um fenômeno recorrente, assim como é recorrente a aspiração por refúgio e segurança em outro local.

Esse artigo visou proporcionar uma compreensão da constituição do instituto do refúgio e sua consolidação sob uma perspectiva coletiva (jurídico-social) e individualista, atentando para a Convenção de 1951 e o Protocolo de 1967, e forneceu bases teóricas para refletir sobre a problemática do refugiado, mais especialmente sobre a tradição latino-americana de proteção ao refugiado.

Outro aspecto ressaltado é a consolidação do Instituto do Refúgio, tanto na sua perspectiva coletiva, em sua abordagem jurídica (1920-1935) e social (19351939), quanto na perspectiva individualista (1938-1950) que evolui até a Convenção de 1951.

A perspectiva coletiva compreende o período de 1921 a 1939, quando os refugiados eram definidos coletivamente por serem parte de determinado grupo étnico ou nacional. A partir de 1938, a ênfase das definições jurídicas do conceito de refugiado deslocou-se para o indivíduo e seu caso pessoal (elemento subjetivo), o que criou a necessidade do estabelecimento de um procedimento de análise. $\mathrm{O}$ aparecimento do segundo critério, mais enfocado na realidade da experiência da perseguição, foi definitivamente influenciado pela ascensão do Nazismo, na Alemanha, em 1933, que imediatamente desencadeou perseguições em massa. A evolução do Direito Internacional dos Refugiados intensificou-se entre 1938 e1950, em particular no referente à determinação do status de refugiado. Não era mais suficiente ser membro de um grupo de deslocados ou apátridas, mas passou a ser requerida uma análise das razões de cada solicitante para o reconhecimento como refugiado.

A Convenção de 1951 é considerada o eixo fundador do Direito Internacional dos Refugiados, já que define quem é refugiado, conceito utilizado até os dias de hoje, e padroniza os tratamentos para aqueles abrigados sob essa definição. Além disso, representa um marco na emergência de uma vontade global em encaminhar os problemas de deslocamentos forçados.

Entretanto, no intento de superar as fraquezas e temporalidade, devido a sua constituição em circunstâncias bastante diferentes de hoje, as políticas que têm sido avançadas em várias regiões são destinadas para cobrir áreas de fraquezas que se encontram na Convenção de 1951 e para ajudar a conformar-se ao direito internacional de refugiados para as diversas questões de refugiados regionais. A essência das políticas regionais é em um esforço para fornecer suporte da comunidade internacional em resolver ou, pelo menos, atenuando problemas dos refugiados.

\section{Referências}

ACNUR. An Introduction to International Protection: Protecting Persons of Concern to UNHCR. Geneva: Office of the United Nations High Commissioner for Refugees, 2005a.

ACNUR. Conference of Plenipotentiaries on the Status of Refugees and Stateless Persons: Summary Record of the Nineteenth Meeting. Disponível em: <http://www.unhcr.org/ refworld/docid/3ae68cda4.html>. Acesso em: 9 dez. 2013a.

ACNUR. Convenção de 1951 Relativa ao Estatuto dos Refugiados. Disponível em: <http://www2.mre.gov.br/ dai/refugiados.htm>. Acesso em: 12 abr. 2013 b.

ACNUR. Los derechos humanos y la protección de los refugiados. Genebra: Alto Comisionado de las Naciones Unidas para los Refugiados, 2008. v. 1. 
ACNUR. Refugiados: legislación y estándares internacionales básicos. Ciudad de Mexico: Oficina Regional del ACNUR para México, Cuba y América Central, 2005b.

ACNUR. States Parties to the 1951 Convention relating to the Status of Refugees and the 1967 Protocol. Disponível em: <http://www.unhcr.org/cgi-bin/texis/vtx/protect/ opendoc.pdf?tbl=PROTECTION\&id=3b73b0d63>. Acesso em: 9 dez. 2013c.

AGAMBEN, Giogio. Al di là dei diritti dell'uomo. In: Mezzi senza fini: note sulla politica. Torino:

Bollati Boringhieri, 1996. p. 20-29.

ARENDT, Hannah. Origens do totalitarismo: antisemitismo, imperialismo, totalitarismo. São Paulo: Companhia das Letras, 1989.

BARBOSA, Luciano Pestana; HORA, José Roberto Sagrado da. A Polícia Federal e a proteção internacional dos refugiados. Brasília: ACNUR, 2006.

BONAMINI, Claudia. Lo status di rifugiato Nell'Unione Europea. 2003-2004. Tesi di Laurea - Università Degli Studi Di Padova. Facoltà di Scienze Politiche. Indirizzo Politico-Internazionale. Padova, 2003-2004.

CARNEIRO, Wellington Pereira. As mudanças nos ventos e a proteção dos refugiados. Universitas: Relações Internacionais, Brasília, v. 3, n. 2, 2005.

CREPEAU, François. Droit d'asile: de l'hospitalité aux contrôles migratoires. Bruxelles: édition Bruylant, édition de l'Université de Bruxelles, 1995.

DOLINGER, Jacob. Direito internacional privado: parte geral. Rio de Janeiro: Renovar, 1996.

FERNANDEZ, Jaime Esponda. La tradición latinoamericana de asilo y la protección internacional de los refugiados. In: FRANCO, Leonardo (Coord.). El asilo e la protección internacional de los refugiados en América Latina. San José: Editorama, 2004. p. 79-125.

FISCHEL DE ANDRADE, José Henrique. A política de proteção a refugiados da Organização das Nações Unidas: sua Gênese no Período Pós-Guerra (1946 1952). 2006. Tese (Doutorado) - Instituto de Relações Internacionais. Doutorado em Relações Internacionais, Universidade de Brasília, Brasília, 2006.

FISCHEL DE ANDRADE, José Henrique. Breve reconstituição histórica da tradição que culminou na proteção internacional dos refugiados. In: ARAÚJO, Nádia de; ALMEIDA, Guilherme Assis de (Coord.). O direito internacional dos refugiados: uma perspectiva brasileira. Rio de Janeiro: São Paulo: Renovar, 2001a. p. 99-125.
FISCHEL DE ANDRADE, José Henrique. Direito internacional dos refugiados: evolução histórica 19211952. Rio de Janeiro: Renovar, 1996.

FISCHEL DE ANDRADE, José Henrique. O Brasil e a Organização Internacional para os Refugiados (19461952). Revista Brasileira de Política Internacional, Brasília, n. 48, p. 60-96, 2005.

FRANCE. La Constitution du 24 juin 1793. Disponível em: <http://www.aidh.org/Biblio/Text_fondat/FR_04. htm>. Acesso em: 14 out. 2013.

GOODWIN-GILL, Guy. The Refugee in International Law. Oxford: Oxford University Press, 1996.

HATHAWAY, James. C. A Reconsideration of the Underlying Premise of Refugee Law. Harvard International Law Journal, Boston, v. 31, n. 1, p. 129-147, 1990.

JUBILUT, Liliana Lyra. O direito internacional dos refugiados e sua aplicação no ordenamento jurídico brasileiro. São Paulo: Método, 2007.

LAFER, Celso. A reconstrução dos direitos humanos: um diálogo com o pensamento de Hannah Arendt. São Paulo: Companhia das Letras, 1988.

LEAGUE OF NATIONS. Additional Protocol to the Provisional Arrangement and to the Convention concerning the Status of Refugees Coming from Germany, 14 September 1939. League of Nations Treaty Series, v. CXCVIII, n. 4634, p. 141. Disponível em: <http://www. unhcr.org/refworld/docid/3dd8d1fb4.html>. Acesso em: 12 jun. 2013.

LEAGUE OF NATIONS. Arrangement With Regard to the Issue of Certificates to Russian Refugees, 5 July 1922. League of Nations, Treaty Series, v. 13, n. 355. Disponível em: <http://www.unhcr.org/refworld/ docid/3dd8b4864.html>. Acesso em: 12 jun. 2013.

LEAGUE OF NATIONS. Arrangement Relating to the Issue of Identify Certificates to Russian and Armenian Refugees. 12 May 1926. League of Nations, Treaty Series, v. LXXXIX, n. 2004. Disponível em: <http://www.unhcr. org/refworld/docid/3dd8b5802.html>. Acesso em: 12 jun. 2013.

LEAGUE OF NATIONS. Arrangement Relating to the Legal Status of Russian and Armenian Refugees. 30 June 1928. League of Nations Treaty Series. v. LXXXIX, n. 2005. Disponível em: <http://www.unhcr.org/refworld/ docid/3dd8cde56.html>. Acesso em: 12 jun. 2013. 
LEAGUE OF NATIONS. Convention Relating to the International Status of Refugees. 28 October 1933. League of Nations, Treaty Series. v. CLIX, n. 3663. Disponível em: <http://www.unhcr.org/refworld/docid/3dd8cf374. html>. Acesso em: 12 jun. 2013.

LEAGUE OF NATIONS. Convention concerning the Status of Refugees Coming From Germany. 10 February 1938. League of Nations Treaty Series. v. CXCII, n. 4461, page 59. Disponível em: <http://www.unhcr.org/refworld/ docid/3dd8d12a4.html>. Acesso em: 12 jun. 2013.

LEAGUE OF NATIONS. Provisonal Arrangement concerning the Status of Refugees Coming from Germany. 4 July 1936. League of Nations Treaty Series, v. CLXXI, n. 3952. Disponível em: <http://www.unhcr.org/refworld/ docid/3dd8d0ae4.html>. Acesso em: 12 jun. 2013.

LOESCHER, Gil. Beyond Charity: International Cooperation and the Global Refugee Crisis. Oxford: Oxford University Press, 1993.

MADEIRA, Hélcio Maciel França. Introdução a História do Direito Português. Disponível em: <http:// helciomadeira.sites.uol.com.br/hd2_arquivos/Almeida_ IHDP.pdf > . Acesso em: 12 abr. 1013.

MOREIRA, Julia Bertino. A questão dos refugiados no contexto internacional (de 1943 aos dias atuais). 2006. Dissertação (Mestrado) -Programa de Pós-Graduação em Relações Internacionais da Unesp, Universidade Estadual Paulista., Unicamp e PUC-SP, São Paulo, 2006.

MESA NACIONAL PARA LAS MIGRACIONES, REPUBLICA DOMINICANA. Seminario sobre Asilo, Refugio y Non-Refoulement: a 20 años de la Declaración de Cartagena sobre Refugiados. Santo Domingo, Republica Dominicana: Facultad Latinoamericana de Ciencias Sociales (FLACSO), 2004.

PIOVESAN, Flávia. Direitos humanos e o direito constitucional internacional. São Paulo: Max Limonad, 2004.

PROTOCOLO SOBRE O ESTATUTO DOS REFUGIADOS. 1967. In: ARAUJO, Nadia; ALMEIDA, Guilherme Assis de (Coord.). O direito internacional dos refugiados: uma perspectiva brasileira. Rio de Janeiro: Renovar, 2001. p. 413-419.
REIS FILHO, Daniel Aarão; FERREIRA, Jorge; ZENHA, Celeste (Org.). O século XX. O tempo das crises: revoluções, fascismos e guerras. Rio de Janeiro: Civilização Brasileira, 2000. v. 2.

RODRIGUES, José Noronha. A história do direito de asilo no direito internacional. CEEAplA WP No18/2006. Ponta Delgada (Portugal): Centro de Estudos de Economia aplicada do Atlântico, 2006.

SANTIAGO, Jaime Ruiz de. Derechos Humanos $y$ Protección Internacional de los Refugiados: XV CDI(1989). Washington: OEA, 1989.

SÉGUR, Philippe. La crise $d u$ droit d'asile. Paris: Presse Universitaires de France, 1998.

SMERALDI, Simona. Il Diritto di Asilo Nell'Unione Europea. 2005. Tesi di Laurea in Diritto dell'Unione Europea - Università Degli Studi Di Roma "La Sapienza”. Facoltà di Scienze Politiche. Indirizzo PoliticoInternazionale. Roma, 2005.

TRINDADE, Antônio Augusto Cançado. Tratado de direito internacional dos direitos humanos. 2. ed. Porto Alegre: S. A. Fabris, 2003.

UNITED NATIONS GENERAL ASSEMBLY. Refugees and Displaced Persons (Constitution of the International Refugee Organization). 15 December 1946. A/RES/62. Disponível em: <http://www.unhcr.org/refworld/ docid/3b00f1963c.html>. Acesso em: 14 out. 2013.

UNITED NATIONS GENERAL ASSEMBLY. Refugees and stateless persons. 3 December 1949. A/RES/319. Disponível em: <http://www.unhcr.org/refworld/ docid/3b00f1ed34.html>. Acesso em: 14 out. 2013.

UNITED NATIONS GENERAL ASSEMBLY. Statute of the Office of the United Nations High Commissioner for Refugees. 14 December 1950. A/RES/428(V). Disponível em: <http://www.unhcr.org/refworld/docid/3ae6b3628. html >. Acesso em: 14 out. 2013.

UNITED NATIONS GENERAL ASSEMBLY. Protocol relating to the Status of Refugees. 16 December 1966. A/ RES/2198. Disponível em: <http://www.unhcr.org/ refworld/docid/3b00f1cc50.html $>$. Acesso em: 14 out. 2013. 